\title{
The Allocation of Capital and Time over the Business Cycle
}

\section{Jeremy Greenwood}

Federal Reserve Bank of Minneapolis and University of Western Ontario

\section{Zvi Hercowitz}

Tel Aviv University and Institute for Empirical Macroeconomics

\begin{abstract}
A Beckerian model of household production is developed to study the cyclical allocation of capital and time between market and home activities. The adopted framework treats the business and household sectors symmetrically. In the market, labor interacts with business capital to produce market goods and services, and likewise at home the remaining time (leisure) is combined with household capital to produce home goods and services. The model presented is parameterized and simulated to see whether it can rationalize the observed allocation of capital and time, as well as other stylized facts, for the postwar U.S. economy.
\end{abstract}

\section{Introduction}

There are two striking facts regarding the accumulation of capital in the nonmarket or household sector: (1) The stock of household capital, defined as the combined stock of consumer durables and residential capital, is higher than the stock of business nonresidential capital.

Discussions with John Coleman and Edward Prescott have been extremely helpful in preparing this paper. Also, skillful research assistance from George Hall and comments made by two referees are gratefully acknowledged. Hercowitz thanks the Foerder Institute for financial support. The views expressed herein are those of the authors and not necessarily those of the Federal Reserve Bank of Minneapolis or the Federal Reserve System. 


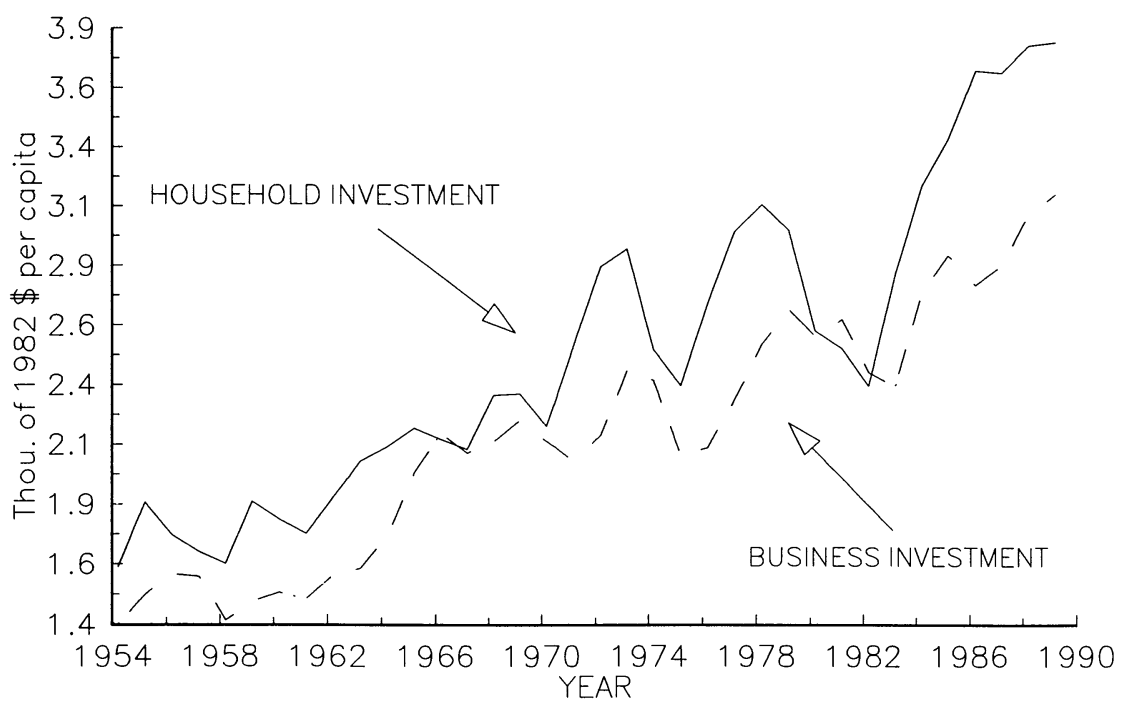

FIG. 1.-U.S. business and household investment, 1954-89

The average ratio between the two capital stocks in the 1954-88 period is 1.13 . (2) Investment in household capital is highly procyclical. As can be seen in figure 1, it moves together with and even leads movements in business investment. Figure 1 also shows the higher level of household investment, which is a reflection of observation 1 .

The first observation indicates that household capital accumulation is quantitatively important. The second highlights its interesting cyclical behavior. The macroeconomic question that arises is, How is the allocation of capital between the business and household sectors over the business cycle determined? The purpose of this paper is to address this question. A macroeconomic model that stresses the role of capital in household activities is developed to study the allocation of capital and time across the two sectors. The theoretical model constructed is parameterized and simulated to see whether it can rationalize the observations above, as well as other stylized facts for the postwar U.S. economy. In particular, a set of second moments for the model's variables - reflecting their variability, persistence, and pattern of comovement-is computed and compared with the corresponding set that characterizes U.S. business cycle fluctuations.

By and large, the business cycle literature is silent on the role of the capital stock held by households. However, some studies, such as Kydland and Prescott (1982) and Christiano (1988), do consider household capital by adding it to business capital and including its services in total consumption. The basic assumption underlying this 
aggregation procedure is that household and business capital are perfect substitutes. For this reason, the composition of total capital investment between business and household investment is indeterminate. Thus this modeling strategy, which has been useful for the analysis of business fluctuations, is not well equipped to address the question at hand.

Another problem with the perfect substitution assumption arises when taxation of market activity is considered. Although both capital stocks are subject to property taxes, only business capital is subject to income taxation, which is far from being trivial (see Jorgenson and Yun 1986). This creates a significant distortion favoring the accumulation of household capital at the expense of business capital. This feature of the tax system, which is incorporated in the current analysis, is likely to be important for modeling the behavior of business and household investment. In a model with perfect substitution between the two capital stocks, business capital would be driven to zero.

Obviously then, a more complete analysis of capital accumulation requires a framework that assigns to household capital a role distinct from that of business capital. The main methodological issue involved here is the development of a framework to model household activities. In real business cycle models, as advanced by Kydland and Prescott (1982) and Long and Plosser (1983), the household sector is encapsulated in a utility function defined over consumption and leisure that is not affected by physical capital accumulation and technological progress. A simple extension of this approach to the problem at hand would be to include the services of household capital as an additional argument in the utility function. However, given that household activities involve approximately as much capital as business activities and three times as much (nonsleeping) time, it seems reasonable to conjecture, ex ante, that a more detailed treatment of the household sector could prove fruitful. In fact, ex post, such a treatment does provide a better rationalization of the observed pattern of cyclical fluctuations in household investment spending.

To provide a natural structure to this analysis, a Beckerian view of household production is adopted (Becker 1965; Ghez and Becker 1975). ${ }^{1}$ The similarities between market and home activities are stressed by following the extreme methodological strategy of symmetric treatment of both activities. There are two production functions, one for market activities and the other for nonmarket activities. In the first, labor interacts with market capital (equipment and structures) to produce market goods and services. In the second, the remaining

${ }^{1}$ Gronau (1986) surveys the literature on household production. 
time interacts with household capital (consumer durables and residence) to produce home goods and services. For example, watching television, listening to music, or playing with a computer combines time with household capital to produce home goods (entertainment). Utility depends only on the consumption of market and home goods. Nonmarket time affects utility only by being an input in the production of home goods. The basic premise of this paper is that considerations of capital accumulation and technological change are important for activities carried out at home as well as in business. As in the market sector, the productivity of time spent in nonmarket activities depends on the state of knowledge and the stock of capital in the household. The model does incorporate one asymmetry between the two sectors; however, capital goods can be produced in the market sector only. This feature is important in the present context since it affects the allocation of capital across the two sectors over time. Finally, Benhabib, Rogerson, and Wright (this issue) also study the macroeconomic implications of household production theory. The current research, which focuses on the allocation of capital over the business cycle, is a close cousin of their analysis, which stresses the allocation of time.

The paper is organized as follows: Section II presents the model. Next, Section III describes the parameterization of the model and the results from the quantitative analysis. Finally, some concluding comments are offered in Section IV.

\section{The Model}

\section{A. The Economic Environment}

Consider an economy in which the representative household maximizes its expected lifetime utility, as given by

$$
E_{0}\left[\sum_{t=0}^{\infty} \beta^{t} U\left(c_{t}, h_{t}\right)\right], \quad 0<\beta<1,
$$

where $c_{t}$ is consumption of nondurable goods and services purchased in the market, and $h_{t}$ is consumption of goods and services produced at home. The momentary utility function $U$, in addition to having the usual properties, is assumed to be homogeneous of degree $q$.

Market and home production technologies are described by

$$
\text { market: } y_{t}=F\left(k_{t}, z_{t} l_{t}\right)
$$

and

$$
\text { home: } h_{t}=H\left(d_{t}, z_{t}\left(1-l_{t}\right)\right)
$$


where $k_{t}$ is the business capital stock, $d_{t}$ is the household capital stock (consumer durables and residential capital stock), 1 is the household's (normalized) endowment of time, and $l_{t}$ is the part of it allocated to market production. The production functions $F$ and $H$ are both assumed to be homogeneous of degree one. The variable $z_{t}$ represents labor-augmenting technological progress, and it evolves according to

$$
z_{t}=A z_{t-1} \epsilon_{t}, \quad A>1,
$$

where $\epsilon_{t}$ is a stationary random variable with unit mean drawn from the distribution $G\left(\epsilon_{t} \mid \epsilon_{t-1}\right){ }^{2}$

Two examples may help to illustrate the economic environment being envisioned. A meal cooked at home combines food and beverages produced in the market using capital and time with household cooking services that use capital and time at home to create the endgood utility. Other utility-generating activities are engaged in outside the home but can be interpreted in a similar way. Golfing, for example, mixes services provided by the business sector (green and clubhouse facilities that use business capital and labor) with ones provided by the household using household capital (car and golf clubs) and time. In the spirit of Becker (1965), one can interpret $F(\cdot)$ and $H(\cdot)$ as producing intermediate goods, which are then used in $U(\cdot)$ to make the final product, utility. Time, like capital, has no intrinsic worth on its own in this framework, but instead derives its value from what can be done with it.

The two capital stocks evolve as

$$
k_{t+1}=k_{t}\left(1-\delta_{k}\right)+i_{k t}, \quad 0<\delta_{k}<1,
$$

and

$$
d_{t+1}=d_{t}\left(1-\delta_{d}\right)+i_{d t}, \quad 0<\delta_{d}<1,
$$

where $\delta_{k}$ and $\delta_{d}$ are the depreciation rates, $i_{k t}$ is gross business investment in nonresidential market capital, and $i_{d t}$ is household investment.

The constraint applying to market output is

$$
c_{t}+i_{k t}+i_{d t} \leq y_{t} .
$$

\footnotetext{
${ }^{2}$ Prescott (1986, p. 15) states that "to a first approximation, the process on the percentage change on the technology process is a random walk with drift plus some serially uncorrelated measurement error." Another reasonable form for the technology process is $z_{t+1}=A^{t} z_{t}^{\rho} \epsilon_{t}$, where $A>1$ and $\rho \in(0,1)$. As an empirical matter, it turns out to be hard to discriminate between these two technology processes. Benhabib et al. (this issue) treat the second case while allowing the technology shock in the market and nonmarket sectors to be different. This latter feature of their analysis is discussed later.
} 
Note that this is the condition that breaks the symmetry between the two sectors. Capital goods can be produced by the business sector only.

Finally, there is a government present in the economy. It levies taxes on the market income earned by labor and capital at the rates $\tau_{l}$ and $\tau_{k}$. The revenue raised by the government in each period $t$ is rebated back to agents in the form of lump-sum transfer payments in the amount $\mu_{t}$. The government's period $t$ budget constraint is

$$
\mu_{t}=\tau_{k} r_{t} k_{t}+\tau_{l} w_{t} l_{t}
$$

where $r_{t}$ represents the market return on capital and $w_{t}$ the real wage rate.

\section{B. Competitive Equilibrium}

The competitive equilibrium for the economy under study will now be formulated. To this end, let the aggregate state of the world be denoted by the vector $(\mathbf{s}, \boldsymbol{\epsilon})$, where $\mathbf{s} \equiv(d, k, z)$; time subscripts are dropped in standard fashion. Assume that the market wage and rental rates, $w$ and $r$, and per capita transfer payments, $\mu$, can all be expressed as functions of the aggregate state of the world as follows: $w=W(\mathbf{s}, \boldsymbol{\epsilon}), r=R(\mathbf{s}, \boldsymbol{\epsilon})$, and $\mu=M(\mathbf{s}, \boldsymbol{\epsilon})$. Likewise, suppose that $k$ and $d$ evolve in equilibrium according to the laws of motion $k^{\prime}=$ $K(\mathbf{s}, \boldsymbol{\epsilon})$ and $d^{\prime}=D(\mathbf{s}, \boldsymbol{\epsilon})$. Also, in similar fashion, let the law of motion for $z \operatorname{read} z^{\prime}=Z\left(\mathbf{s}, \epsilon^{\prime}\right) \equiv A z \epsilon^{\prime}$. Thus the movement in the vector $\mathbf{s}$ is governed by the transition function $\mathbf{s}^{\prime}=S\left(\mathbf{s}, \boldsymbol{\epsilon}, \epsilon^{\prime} ; K, D\right) \equiv$ $\left(K(\mathbf{s}, \boldsymbol{\epsilon}), D(\mathbf{s}, \epsilon), Z\left(\mathbf{s}, \epsilon^{\prime}\right)\right)$, where the adopted notation serves to emphasize that the function $S$ depends on the forms of the functions $K$ and $D$.

Each period the "representative" household chooses its consumption of market goods, $\tilde{c}$, stocks of business and household capital, $\tilde{k}^{\prime}$ and $\tilde{d}^{\prime}$, and time allocated to market work, $\tilde{l}$, so as to solve the following dynamic programming problem: ${ }^{3}$

$$
\begin{aligned}
V(\tilde{k}, \tilde{d} ; \mathbf{s}, \boldsymbol{\epsilon})=\max _{\left(\tilde{c}, \tilde{k}^{\prime}, \tilde{d}^{\prime}, \tilde{l}\right)}\{U(\tilde{c}, H(\tilde{d}, z(1-\tilde{l}))) \\
\left.+\beta \int V\left(\tilde{k}^{\prime}, \tilde{d}^{\prime} ; \mathbf{s}^{\prime}, \boldsymbol{\epsilon}^{\prime}\right) d G\left(\boldsymbol{\epsilon}^{\prime} \mid \boldsymbol{\epsilon}\right)\right\}
\end{aligned}
$$

\footnotetext{
${ }^{3}$ It is straightforward to introduce irreversible investment into the analysis, albeit at some expense in notation. Let $p_{k}=P_{k}(\mathbf{s}, \boldsymbol{\epsilon})$ and $p_{d}=P_{d}(\mathbf{s}, \boldsymbol{\epsilon})$ represent the prices of business and household capital. When a capital good is being produced in the economy, its price must be unity since any agent can freely transform output into capital. Thus if $K(\mathbf{s}, \boldsymbol{\epsilon})>\left(1-\delta_{k}\right) K$, then $P_{k}(\mathbf{s}, \boldsymbol{\epsilon})=1$; if $D(\mathbf{s}, \boldsymbol{\epsilon})>\left(1-\delta_{d}\right) D$, then $P_{d}(\mathbf{s}, \boldsymbol{\epsilon})=1$. If a capital good is not being produced, then its price must adjust to clear the used market
} 
subject to

$$
\begin{aligned}
\tilde{c}+\tilde{k}^{\prime}+\tilde{d}^{\prime}= & \left(1-\tau_{k}\right) R(\mathbf{s}, \boldsymbol{\epsilon}) \tilde{k}+\left(1-\tau_{l}\right) W(\mathbf{s}, \boldsymbol{\epsilon}) \tilde{l} \\
& +\left(1-\delta_{k}\right) \tilde{k}+\left(1-\delta_{d}\right) \tilde{d}+M(\mathbf{s}, \boldsymbol{\epsilon})
\end{aligned}
$$

and $\mathbf{s}^{\prime}=S\left(\mathbf{s}, \boldsymbol{\epsilon}, \boldsymbol{\epsilon}^{\prime} ; K, D\right)$.

Similarly, the representative firm hires capital and labor, $\hat{k}$ and $\hat{l}$, in each period so as to maximize profits. Hence, it solves the following problem:

$$
\max _{\hat{k}, \hat{l}}\{F(\hat{k}, z \hat{l})-R(\mathbf{s}, \boldsymbol{\epsilon}) \hat{k}-W(\mathbf{s}, \boldsymbol{\epsilon}) \hat{l}\}
$$

Needless to say, the firm earns zero profits each period because of the constant-returns-to-scale assumption.

The competitive equilibrium under study is now formally defined, where again $(\mathbf{s}, \boldsymbol{\epsilon})=(k, d, z, \boldsymbol{\epsilon})$.

Definition. A competitive equilibrium is a set of allocation rules, $c=C(k, d, z, \epsilon), k^{\prime}=K(k, d, z, \epsilon), d^{\prime}=D(k, d, z, \epsilon)$, and $l=L(k, d$, $z, \epsilon)$, and pricing and transfer functions, $r=R(k, d, z, \epsilon), w=W(k$, $d, z, \boldsymbol{\epsilon})$, and $\mu=M(k, d, z, \boldsymbol{\epsilon})$, such that ${ }^{4}$

i) households solve problem (P1), taking as given the aggregate state of the world $(k, d, z, \epsilon)$ and the form of functions $R(\cdot), W(\cdot), M(\cdot)$, $K(\cdot)$, and $D(\cdot)$, with the solution to this problem having the form $\tilde{c}=C(k, d, z, \epsilon), \tilde{k}^{\prime}=K(k, d, z, \epsilon), \tilde{d}^{\prime}=D(k, d, z, \epsilon)$, and $\tilde{l}=L(k$, $d, z, \epsilon)$;

ii) firms solve problem (P2), given $(k, d, z, \epsilon)$ and the functions $R(\cdot)$ and $W(\cdot)$, with the solution to this problem having the form $\hat{k}=$ $k$ and $\hat{l}=L(k, d, z, \epsilon)$; and

iii) the goods market clears each period, implying that

$$
c+k^{\prime}+d^{\prime}=F(k, z l)+\left(1-\delta_{k}\right) k+\left(1-\delta_{d}\right) d .
$$

It is easy to deduce from the definition for a competitive equilib-

for it. Consequently, if $K(\mathbf{s}, \boldsymbol{\epsilon})=\left(1-\delta_{k}\right) K$, then $P_{k}(\mathbf{s}, \boldsymbol{\epsilon}) \leq 1$; if $D(\mathbf{s}, \boldsymbol{\epsilon})=\left(1-\delta_{d}\right) D$, then $P_{d}(\mathbf{s}, \epsilon) \leq 1$. The household's budget constraint (8) now appears as

$$
\begin{aligned}
c+P_{k}(\mathbf{s}, \boldsymbol{\epsilon}) k^{\prime}+P_{d}(\mathbf{s}, \boldsymbol{\epsilon}) d^{\prime}= & \left(1-\tau_{k}\right) R(\mathbf{s}, \boldsymbol{\epsilon}) k+\left(1-\tau_{l}\right) W(\mathbf{s}, \boldsymbol{\epsilon}) l+P_{k}(\mathbf{s}, \boldsymbol{\epsilon})\left(1-\delta_{k}\right) k \\
& +P_{d}(\mathbf{s}, \boldsymbol{\epsilon})\left(1-\delta_{d}\right) d+M(\mathbf{s}, \boldsymbol{\epsilon}) .
\end{aligned}
$$

The classic treatment of this problem is contained in Sargent (1980). In the simulations undertaken, the irreversibility constraints, $K(\mathbf{s}, \boldsymbol{\epsilon}) \geq\left(1-\delta_{k}\right) K$ and $D(\mathbf{s}, \boldsymbol{\epsilon}) \geq\left(1-\delta_{d}\right) D$, are never binding for two reasons: first, the economy is growing over time and, second, the stock of old capital depreciates each period.

${ }^{4}$ This definition presupposes that at the start of time the initial conditions $k=\tilde{k}$ and $d=\tilde{d}$ hold; i.e., at the time the world begins, the aggregate stocks of business and household capital should coincide with the stocks of business and household capital held by the representative household. 
rium that the allocation rules for $c, k^{\prime}, d^{\prime}$, and $l$ are implicitly defined by the following system of equations, in addition to the aggregate resource constraint (9):

$$
\begin{aligned}
& U_{1}(c, h)=\beta \int U_{1}\left(c^{\prime}, h^{\prime}\right)\left[\left(1-\tau_{k}\right) F_{1}\left(k^{\prime}, z^{\prime} l^{\prime}\right)+\left(1-\delta_{k}\right)\right] d G\left(\epsilon^{\prime} \mid \epsilon\right), \\
& U_{1}(c, h)=\beta \int U_{1}\left(c^{\prime}, h^{\prime}\right)[ H_{1}\left(d^{\prime}, z^{\prime}\left(1-l^{\prime}\right)\right) \\
& \times\left.\frac{U_{2}\left(c^{\prime}, h^{\prime}\right)}{U_{1}\left(c^{\prime}, h^{\prime}\right)}+\left(1-\delta_{d}\right)\right] d G\left(\epsilon^{\prime} \mid \epsilon\right),
\end{aligned}
$$

and

$$
\left(1-\tau_{l}\right) z F_{2}(k, z l)=\frac{U_{2}(c, h)}{U_{1}(c, h)} z H_{2}(d, z(1-l))
$$

recall that $h=H(d, z(1-l))$.

Equations (10), (11), and (12) combine the efficiency conditions associated with the household's problem (P1) together with those of the firm's problem (P2). The first-order conditions connected with (P1) govern the accumulation of business and household capital in addition to the allocation of time, given the rental and wage rates $r$ and $w$; the conditions from (P2) equate these rates to the marginal products of business capital and market time, $F_{1}(k, z l)$ and $z F_{2}(k, z l)$. Finally, note that the economy's resource constraint (9) can be obtained by substituting (7) into (8) while making use of parts $i$ and ii of the definition for a competitive equilibrium.

In order to put the implications of the present framework for the allocation of time into perspective, consider the standard paradigm used in business cycle analysis. There, a homothetic momentary utility function $U(c, 1-l)$ defined over consumption $c$ and leisure $1-l$ is used. The optimality condition governing the allocation of time appears as

$$
\frac{U_{2}(c, 1-l)}{U_{1}(c, 1-l)} \equiv \Gamma\left(\frac{c}{1-l}\right)=\left(1-\tau_{l}\right) w,
$$

with the form of the function $\Gamma$ following from the assumed homotheticity of $U$. Note that for this paradigm to be consistent with secular increases in real wages and consumption on the one hand and a stationary allocation of time to market work on the other, a unit elasticity of substitution between consumption and leisure is required..$^{5}$

\footnotetext{
${ }^{5}$ Kydland (1984) shows that within the constant elasticity of substitution (CES) family of utility functions, only the specification corresponding to unitary elasticity (the Cobb-
} 
A related important implication of (13), which has played a crucial role in neoclassical macroeconomic thinking, is that for real wage movements to have strong effects on market labor, they should, at least partly, be transitory. With equation (13) and intuitive reasoning from the permanent income hypothesis, when $w$ increases only temporarily, it has a minor effect on $c$. Hence, (13) implies an expansion of market work. For the case in which $w$ moves permanently, it has a stronger effect on $c$, which reduces the extent to which market labor reacts.

By contrast, from (12), the condition for optimal allocation of time in the present model is

$$
z H_{2}(d, z(1-l)) \frac{U_{2}(c, h)}{U_{1}(c, h)}=\left(1-\tau_{l}\right) z F_{2}(k, z l)=\left(1-\tau_{l}\right) w .
$$

Here technological progress and capital accumulation, which affect market productivity and hence the real wage, also affect home productivity. Hence, stationarity of market hours does not restrict the elasticity of substitution in utility. It requires now that technological progress and capital accumulation affect the two marginal productivities of labor in a parallel way. For this to be the case, the two production functions should display constant returns to scale, the utility function over $c$ and $h$ should be homogeneous of arbitrary degree, and technological progress should be representable as labor augmenting. Observe that two new factors will now influence the allocation of time between market and nonmarket activities. The first is the relative price of household goods (in terms of market goods), $U_{2}(c$, $h) / U_{1}(c, h)$. The second is the degree of substitution between household capital, $d$, and (effective) nonmarket time, $z(1-l)$, in home production.

\section{Quantitative Analysis: Calibration and Simulation}

In this section of the paper, a parametric version of the model is calibrated, simulated, and evaluated. The dynamics of the simulated economy are compared with the behavior of annual U.S. data for

Douglas form) is consistent with balanced growth with stationary labor time. As shown in King, Plosser, and Rebelo (1988a, 1988b), the same holds with the more general structure

$$
U(c, 1-l)= \begin{cases}\frac{c^{1-\gamma}}{1-\gamma} V(1-l) & \text { if } 0<\gamma \text { and } \gamma \neq 1 \\ \ln c+V(1-l) & \text { if } \gamma=1,\end{cases}
$$

where $V(\cdot)$ is such that $U(\cdot)$ satisfies the standard properties. 
the sample period 1954-89. Specifically, the question addressed is whether the model is able to mimic the observed behavior of investment in household and market production, as well as other features of business fluctuations.

So as to impose some discipline on the simulation conducted, the calibration procedure advanced by Kydland and Prescott (1982) is adopted (for an introduction to this literature, see Prescott [1986] and Danthine and Donaldson [1991]). An important feature of this approach is that as many model parameters as possible are set in advance (i) on the basis of a priori information about their magnitudes or (ii) so that along a deterministic balanced growth path, the ratios for various endogenous variables in the model correspond to their average values for the U.S. postwar period. Hence prior information and the first moments of the data are stressed in setting parameter values. The implications of different values for free parameters - in the present case there will be only one-can be studied by simulating the model. The shocks to the system are the $z$ process, whose moments are set to match the sample moments observed for the corresponding productivity measures from the market data.

Specifically, the procedure is the following: First, the model is given a suitable parametric form and calibrated. Then it is transformed into a stationary representation. Next, the allocation rules for the stationary model are computed. With these allocation rules, 5,000 artificial samples of 36 observations (the number of years in the 1954-89 sample) for each variable of interest are simulated. Each simulation corresponds to a randomly generated sample of 36 realizations of $\epsilon$ and the corresponding $z$-process. Then the data from the model are transformed back to their nonstationary form and detrended using the Hodrick-Prescott filter. ${ }^{6}$ The average moments over the 5,000 samples are computed and compared to the corresponding moments of the actual Hodrick-Prescott-filtered U.S. data. The transformation procedure used and the solution algorithm employed are detailed in the Appendix.

The unit of time for the quantitative analysis is a year. This time unit was chosen for two reasons. First, the stochastic process governing technological change in the household sector is identified in the current framework through the assumption that technological change in the business sector is governed by the same process. The implication that labor-augmenting innovations in technology affect

\footnotetext{
${ }^{6}$ For the reader unfamiliar with the real business cycle literature, the HodrickPrescott filter fits a smooth, slowly varying curve through time-series data. See Prescott (1986) and Danthine and Donaldson (1991) for more detail.
} 
both sectors simultaneously is more realistic the longer the basic time period. While a year is probably too short in this regard, it is preferable to a quarter. Second, an additional benefit of this time unit in the current context, which stresses capital accumulation, is the implied 1-year time to build for capital. Investment becomes part of the capital stock with a simple to model 1-year delay. This implication of the time unit seems reasonable and is in line with the analysis of Kydland and Prescott (1982), who used a quarterly model with a more elaborate time-to-build structure spread out over four quarters.

Finally, some care must be taken when matching up the theoretical constructs of the model with their counterparts in the U.S. data. Gross national product includes in it a measure of the service flow from the economy's housing stock. Gross housing product is made up of the value added from commercial residential renting plus an imputed value added from owner-occupied homes. For the purposes of the current analysis, the product from the economy's housing stock should be counted as part of nonmarket production and therefore netted out of GNP. Thus, in the data, market output is taken to be GNP less gross housing product. The data analogue for market consumption in the model is personal consumption expenditure on nondurable goods and services. Again, the value of services from housing is subtracted. The durable goods component of personal consumption expenditure is added to residential investment to obtain a measure of investment in household capital in the data. Similarly, business investment is represented by fixed nonresidential investment in equipment and structures.

\section{A. Specification of the Economy}

To begin with, let tastes and technology be specified in the following way:

$$
\begin{gathered}
U(c, h)=\frac{1}{1-\gamma}\left[\theta c^{\sigma}+(1-\theta) h^{\sigma}\right]^{(1-\gamma) / \sigma}-\frac{1}{1-\gamma}, \\
F(k, z l)=k^{\alpha}(z l)^{1-\alpha},
\end{gathered}
$$

and

$$
H(d, z(1-l))=\left\{\omega d^{\lambda}+(1-\omega)[z(1-l)]^{\lambda}\right\}^{1 / \lambda},
$$

where $\sigma, \lambda \leq 1, \gamma>0$, and $0<\alpha, \theta, \omega<1$. Preferences and household production have been given CES functional forms, while market production has a Cobb-Douglas characterization, that is, a CES with unit elasticity of substitution. Note that under this specification the term $z^{1-\alpha}$ in (16) will correspond to the "Solow residual" as it is conventionally defined in the business cycle literature. 
The stochastic structure of the model is described by a two-state Markov process. Specifically, in any given period the technology shock, $\epsilon$, is assumed to be drawn from the time-invariant two-point set $\mathscr{E}=\left\{e^{\xi_{1}}, e^{\xi_{2}}\right\}$. The distribution function governing next period's technology shock, $\epsilon^{\prime}$, conditional on the current realization, $\epsilon$, is defined by $\operatorname{prob}\left[\epsilon^{\prime}=e^{\xi_{s}} \mid \epsilon=e^{\xi_{r}}\right]=\pi_{r s}$, where $0 \leq \pi_{r s} \leq 1$, for $r, s=$ $1,2$.

\section{B. Calibration Procedure and Benchmark Model Results}

In the first stage of the quantitative analysis, attention is directed to a special version of the model with the following properties: (i) technological change does not play any role in decisions of the household sector and (ii) the services from household capital enter the utility function in an additive manner. Hence, this version of the model can be seen as a "straw man" that downplays the household production structure, incorporating the minimal requirement for households to demand capital.

Features i-ii are achieved as follows: First, both preferences and household production are restricted to have unitary elasticity of substitution (i.e., $\sigma=\lambda=0$ ), so that they assume the form

$$
U(c, h)=\frac{1}{1-\gamma}\left(c^{\theta} h^{1-\theta}\right)^{1-\gamma}-\frac{1}{1-\gamma}
$$

and

$$
H(d, z(1-l))=d^{\omega}[z(1-l)]^{1-\omega} .
$$

Substituting (19) into (18) yields

$$
\begin{aligned}
\underline{U}(c, 1-l, d, z)= & \frac{1}{1-\gamma} \\
& \times\left[c^{\theta}(1-l)^{(1-\omega)(1-\theta)} d^{\omega(1-\theta)} z^{(1-\omega)(1-\theta)}\right]^{1-\gamma}-\frac{1}{1-\gamma} .
\end{aligned}
$$

The stock of household capital enters $\underline{U}$ in a similar way as in the utility function used by Macklem (1989) and others (see the references therein).

Second, $\gamma$ is chosen to be one so that $\underline{U}$ becomes

$$
\begin{aligned}
\underline{U}(c, 1-l, d, z)= & \theta \ln c+(1-\omega)(1-\theta) \ln (1-l)+\omega(1-\theta) \ln d \\
& +(1-\omega)(1-\theta) \ln z .
\end{aligned}
$$

Note that (21) satisfies the criteria $\mathrm{i}-\mathrm{ii}$. The choice regarding $l$ has the standard form (eq. [13]) with unit elasticity of substitution between $c$ 
and $1-l$, and technological change in home production does not affect any household decisions.

In order to implement the benchmark model, values for the following parameters need to be chosen: utility: $\theta$ and $\beta$; market production: $\alpha$; home production: $\omega$; depreciation rates: $\delta_{k}$ and $\delta_{d}$; technology process: $A, \xi_{1}, \xi_{2}, \pi_{11}$, and $\pi_{22}$; and tax rates: $\tau_{k}$ and $\tau_{l}$.

First, the number of parameters is reduced by imposing symmetry on the stochastic technology process. It is assumed that $\xi_{1}=-\xi_{2}=$ $\xi$ and that $\pi_{11}=\pi_{22}=\pi$. Then $\xi$ is the standard deviation of the shock and $\rho=2 \pi-1$ is the coefficient of serial correlation. In market production, $\alpha$ is chosen to be 0.3 , given that labor's share of GNP net of housing was about 70 percent during the 1954-89 sample period. For utility, since the time unit is a year, $\beta$ is set equal to the standard value of 0.96 .

The depreciation rate on market capital $\delta_{k}$ is chosen to be 7.8 percent, a value derived from the average service life of nonresidential structures and equipment for the period $1954-85 .{ }^{7}$ It is assumed that the average depreciation rate of household capital $\delta_{d}$, which consists of components similar to the structures and equipment in business capital, is equal to $\delta_{k}$.

The parameters of the $z$-process require the calculation of the Solow residuals from the U.S. data and their sample moments. This calculation was carried out using GNP (net of housing) for market output and data on net fixed nonresidential private capital and total work-hours employed for factor inputs. The average growth rate of $z$ is 0.01 ; hence $A$ was equated to 1.01 . The first difference of the $\log$ of the Solow residual, corresponding to $\ln A+\ln \epsilon$, has a standard deviation of 0.022 and an autocorrelation coefficient of 0.16 , which is statistically insignificantly different from zero. Hence, $\xi=0.022$ and $\rho$ was set to zero, implying that $\pi=0.5$.

The tax rate $\tau_{k}$, applying in the model to gross capital income, was set equal to 0.25 . On the deterministic balanced growth path and given the values of $\delta_{k}$ and $\beta$ described above, this corresponds to a tax rate on net capital income of about 50 percent. This figure is between the effective tax rates of 52 percent on corporate capital income and 40 percent on noncorporate capital income computed by Jorgenson and Yun (1986). Regarding the tax rate on labor income, prior to the Tax Reform Act of 1986 the marginal tax rates on personal income ranged from 11 percent to 50 percent. In this range, $\tau_{l}$ $=0.25$ was picked ${ }^{8}$

\footnotetext{
${ }^{7}$ This figure is taken from Fixed Reproducible Tangible Wealth in the United States, 1925-1985, a publication of the U.S. Department of Commerce (1987).

${ }^{8}$ This seems in line with the tax rates reported in Hausman and Poterba (1987).
} 
Two parameters still remain: $\theta$ in utility and $\omega$ in home production. Two first moments computed from the U.S. data are relevant for the determination of these parameters: $(a)$ the average ratio of total hours worked to total nonsleeping hours of the working age population (16 hours per day) is 0.24 , and $(b)$ the average ratio of household capital to market capital is $1.13 .{ }^{9}$ The values of $\theta$ and $\omega$ were chosen so that these two first moments are satisfied along the model's balanced growth path. ${ }^{10}$

Specifically, along the balanced growth path for the model, all variables grow at the same rate as $z$, or at the gross rate $A$; see the Appendix for more detail. Thus $c^{\prime} / c=k^{\prime} / k=d^{\prime} / d=z^{\prime} l^{\prime} / z l=z^{\prime}(1-$ $\left.l^{\prime}\right) / z(1-l)=A$. Given the current parameterization for tastes and technology, the balanced growth path analogues to equations (10), (11), (12), and (9) are

$$
\begin{aligned}
& 1=\beta A^{-\gamma}\left(1-\tau_{k}\right)\left[\alpha\left(\frac{k}{z l}\right)^{\alpha-1}+\left(1-\delta_{k}\right)\right], \\
& 1=\beta A^{-\gamma}\left\{\frac{\omega[(1-\theta) / \theta] c}{d}+\left(1-\delta_{d}\right)\right\} \\
&=\beta A^{-\gamma}\left\{\frac{\omega[(1-\theta) / \theta](c / z)}{d / z}+\left(1-\delta_{d}\right)\right\}, \\
&\left(1-\tau_{l}\right)(1-\alpha)\left(\frac{k}{z l}\right)^{\alpha}=\frac{(1-\omega)[(1-\theta) / \theta] c}{z(1-l)},
\end{aligned}
$$

and

$$
c=k^{\alpha}(z l)^{1-\alpha}-A k+\left(1-\delta_{k}\right) k,
$$

${ }^{9}$ The first average was calculated by taking the mean over the 1954-89 sample period of total weekly hours of work (from the Household Survey) divided by population aged 16-64 times 7 days times 16 hours per day.

${ }^{10}$ Recall that there is no notion of leisure in the model. This simplifies the quantitative analysis. Here time and capital are simply divided into their market and nonmarket components. Leisure could be incorporated into the model by subdividing nonmarket time into homework and leisure time. One person's recreation is another person's toil. Should household activities such as exercising, gardening, or renovating be counted as work or leisure, and, similarly, should business activities such as entertaining be considered leisure or work? According to Becker (1965, p. 504), "although the social philosopher might have to define precisely the concept of leisure, the economist can reach all his traditional results as well as many more without introducing it at all." Gronau (1986) provides an operational definition of leisure by defining work at home to be those activities one could hire someone else to do. He suggests that it is impossible to enjoy leisure vicariously. There are some cross-sectional data that break down nonmarket time into homework and leisure time. More problematic for the questions being addressed here, though, would be undertaking the corresponding breakdown for the stock of household capital. The two hypotheses are likely to be observationally equivalent, Gronau suggests. Indeed, Benhabib et al. (this issue) include leisure time in their study and arrive at conclusions similar to those of the current paper. 
which implies

$$
\frac{c}{z}=\left(\frac{k}{z}\right)^{\alpha}(l)^{1-\alpha}-\frac{A k}{z}+\frac{\left(1-\delta_{k}\right) k}{z} .
$$

The two restrictions above from the long-run data imply

$$
l=0.24
$$

and

$$
\frac{d}{k}=\frac{d / z}{k / z}=1.13
$$

Given values for $\beta, A, \gamma, \alpha, \delta_{k}, \delta_{d}, \tau_{k}$, and $\tau_{l}$, this system of six equations can be thought of as determining a solution for the six unknowns $k / z, d / z, l, c / z, \theta$, and $\omega$. The parameter values obtained for $\omega$ and $\theta$ are 0.13 and 0.26 , respectively.

The values for $k / z, d / z, l$, and $c / z$, as determined by (22), (23), (24), and (25), are sensitive to the tax parameters $\tau_{k}$ and $\tau_{l}$. As one might expect, the taxation of the market income earned by labor and capital induces substitution toward nonmarket activity. For instance, if capital taxation is eliminated in the model, the ratio of household to business capital drops from 1.13 to 0.80 and the ratio of nonmarket to narket time falls from 3.2 to 3.0. The marginal welfare cost of capital taxation along the benchmark economy's balanced growth path is high: 3.4 units of output in lost welfare for each extra unit of output raised in revenue. ${ }^{11}$ The corresponding figure for labor taxation is 0.92 . (These calculations ignore the transitional dynamics from one balanced growth path to another following a tax change.)

Finally, the model's balanced growth path can be used to compute the total amount of goods and services produced in the economy. The aggregate $F(k, z l)+\left[U_{2}(c, h) / U_{1}(c, h)\right] \times H(d, z(1-l))$, where market goods are used as the numeraire, can be denoted gross economic product. Along the model's balanced growth path, the ratio of gross economic product to GNP is 2.9. The large size of this number

${ }^{11}$ Along the balanced growth path, the level of market goods, $c$, home goods, $h$, tax revenue, $\mu$, and welfare, $W$, will be functions of the tax rates $\tau_{k}$ and $\tau_{l}$ (as well as the parameters describing taste and technology). It is straightforward to deduce (see the Appendix) that one can write $c=z c\left(\tau_{k}, \tau_{l}\right), h=z h\left(\tau_{k}, \tau_{l}\right)$, and $\mu=z \mu\left(\tau_{k}, \tau_{l}\right)$, where $c(\cdot), h(\cdot)$, and $\mu(\cdot)$ are time-invariant functions. Consequently, $W$ can be expressed as $W=z^{q} W\left(\tau_{k}, \tau_{l}\right) \equiv z^{q} U\left(c\left(\tau_{k}, \tau_{l}\right), h\left(\tau_{k}, \tau_{l}\right)\right)$, given the assumed homogeneity property of the momentary utility function. (By trivially modifying the line of argument being pursued here, one could add a constant term to the momentary utility function, as in [15].) The marginal welfare cost of capital taxation is defined as

$$
\frac{z^{q} W_{1}\left(\tau_{k}, \tau_{l}\right) / z^{q-1} U_{1}\left(c\left(\tau_{k}, \tau_{l}\right), h\left(\tau_{k}, \tau_{l}\right)\right)}{z \mu_{1}\left(\tau_{k}, \tau_{l}\right)}=\frac{W_{1}\left(\tau_{k}, \tau_{l}\right) / U_{1}\left(c\left(\tau_{k}, \tau_{l}\right), h\left(\tau_{k}, \tau_{l}\right)\right)}{\mu_{1}\left(\tau_{k}, \tau_{l}\right)} .
$$


follows from the fact that household production uses about 1.1 times the capital and 3.2 times the time of market production.

The results of the current simulation are shown in table 1 (under model 1) and in figure 2. By comparing the standard deviations of the variables for model 1 with the ones characterizing the U.S. data, one can see that, in general, the model generates too little variation. For example, the standard deviation of actual GNP around the Hodrick-Prescott trend is 2.3 percent, whereas the model generates a corresponding 1.9 percent. The standard deviation of market labor is particularly low, 0.8 percent, relative to the actual figure of 1.7 percent. One cause of this result is the nature of the technology process. Since $z$ is a random walk, changes in market opportunities for labor are permanent, and hence they generate a weak response of market labor effort. Also given the focus of this paper, mechanisms that enhance labor's responsiveness to market opportunities were not incorporated, such as the intertemporal nonseparability of preferences in Kydland and Prescott (1982) or the indivisibility of market work in Hansen (1985) and Rogerson (1988).

Hours and output are even less variable when the model is transformed into the prototypical real business cycle model (with a CobbDouglas utility function defined over consumption and leisure) by eliminating household capital from the home production function. The standard deviations of output and market hours drop to 1.6 and 0.4 percent in this case. ${ }^{12}$ Given that only the stock of business capital needs to be adjusted following a shock, one can expect market time to react by less. Thus the inclusion of household capital into real business cycle models increases the volatility of output and hours.

The behavior of investment in business and household capital for the benchmark model is shown in figure 2 , which plots the variables $i_{k}$ and $i_{d}$ for an artificial sample of 36 years. It can be clearly seen that the two investments tend to react in opposite directions, with business investment moving much closer to output. Also, fluctuations in invest-

${ }^{12}$ The findings for the model without household capital follow:

\begin{tabular}{lccc}
\hline \hline & $\begin{array}{c}\text { Standard Deviation } \\
(\%)\end{array}$ & Autocorrelation & $\begin{array}{c}\text { Correlation } \\
\text { with Output }\end{array}$ \\
\hline Output & 1.6 & .42 & 1.00 \\
Consumption & 1.1 & .48 & .98 \\
Business investment & 4.3 & .35 & .97 \\
Market time & .4 & .35 & .92 \\
\hline
\end{tabular}

These results were obtained by setting $\omega=0.0004$ in the benchmark model while dropping eq. (27) from the calibration procedure. 
TABLE 1

\begin{tabular}{|c|c|c|c|}
\hline Variable & $\begin{array}{c}\text { Standard } \\
\text { Deviation (\%) }\end{array}$ & $\begin{array}{c}\text { First-Order } \\
\text { Autocorrelation }\end{array}$ & $\begin{array}{c}\text { Cross- } \\
\text { Correlation } \\
\text { with Output }\end{array}$ \\
\hline & \multicolumn{3}{|c|}{ U.S. Annual Data, 1954-89 } \\
\hline Output & 2.3 & .53 & 1.00 \\
\hline Consumption & 1.4 & .61 & .80 \\
\hline Business investment & 6.2 & .45 & .85 \\
\hline Household investment & 7.7 & .44 & .65 \\
\hline \multirow[t]{2}{*}{ Market time } & 1.7 & .46 & .90 \\
\hline & \multicolumn{3}{|c|}{ Model 1} \\
\hline Output & 1.9 & .50 & 1.00 \\
\hline Consumption & 1.0 & .51 & .92 \\
\hline Business investment & 9.2 & -.05 & .69 \\
\hline Household investment & 6.1 & .13 & .34 \\
\hline \multirow[t]{2}{*}{ Market time } & .8 & .52 & .95 \\
\hline & \multicolumn{3}{|c|}{ Model 2} \\
\hline Output & 2.0 & .37 & 1.00 \\
\hline Consumption & 1.0 & .54 & .92 \\
\hline Business investment & 4.1 & .45 & .99 \\
\hline Household investment & 4.9 & .24 & .96 \\
\hline Market time & 1.1 & .32 & .95 \\
\hline
\end{tabular}

NoTE. - The U.S. data were divided by the working age population (16-64) logged and Hodrick-Prescott filtered. Output is GNP less gross housing product. Consumption is personal consumption expenditures on nondurables and services, excluding housing. Business investment is fixed nonresidentral private investment, and household investment is private residential investment plus personal consumption expenditure on durable goods. These quantities are denominated in 1982 dollars. Market time is total hours and is taken from the Current Population Survey (a survey of households).

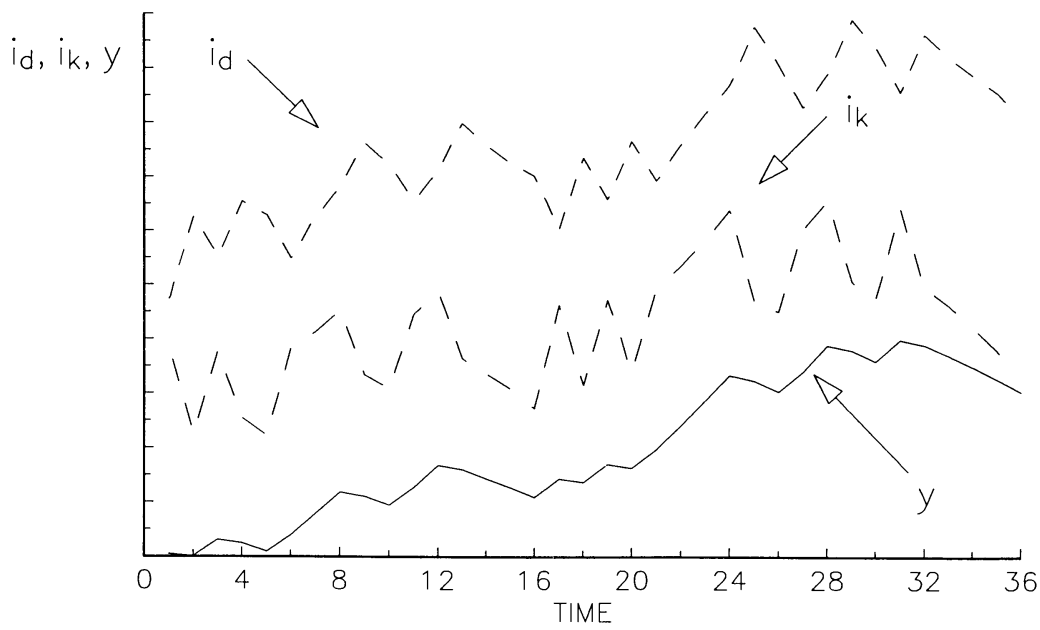

FIG. 2.-Behavior of investment and output: model 1 
ment tend to be short-lived. Only when the fluctuations persist do the two investments begin to comove positively. The short nature of the fluctuations is reflected in the coefficients of serial correlation of $i_{k}$, which is slightly negative $(-.05)$, and of $i_{d}$, which is only weakly positive (.13). By contrast, in the U.S. data, their coefficients of serial correlation are .45 and .44 , respectively. Another lack of correspondence occurs in the relative volatilities. Business investment is less volatile in the data with a standard deviation of 6.2 percent against 7.7 percent for household investment, whereas in model 1 the corresponding figures are 9.2 percent and 6.1 percent.

The negative comovement of the two investments, which stands in contrast with the positive one displayed by actual data (fig. 1), has to do with the basic asymmetry between the two types of capital. Business capital can be used to produce household capital, but not the other way around. When an innovation to technology occurs, say a positive one, the optimal levels for both capital stocks increase. Given the asymmetry in the nature of the two capital goods, the tendency for the benchmark model is to build business capital first, and only then household capital. Capital investment requires abstention from consumption of market goods, but not (directly) from consumption of home goods. The induced short-run scarcity of market consumption goods in terms of nonmarket ones operates to reduce the benefit from immediate investment in household capital vis-à-vis business capital. The short-run scarcity of market consumption goods following a positive technology shock is reflected in the countercyclical behavior of the relative price of home goods (fig. 3), which has a correlation with output of -.81 . The next subsection addresses this question in greater detail.

\section{Departing from the Benchmark Model}

In the benchmark model, market and home production functions were parameterized identically. Given the asymmetric role the two types of capital play in the paradigm and the poor outcome of the earlier simulation, it may be profitable to investigate whether relaxing the assumption of a unitary elasticity of substitution in home production $(\lambda=0)$ can improve the ability of the model to generate the pattern of investment behavior observed in the data. Note that higher values for $\lambda \in(-\infty, 1]$ in (17) imply greater substitutability between $d$ and $z(1-l)$ in household production.

It turns out that reducing the degree of substitution in home production, relative to the Cobb-Douglas case, has strong implications for the pattern of comovements between the two investments. The simulation results obtained when $\lambda=-1$ are reported under model 


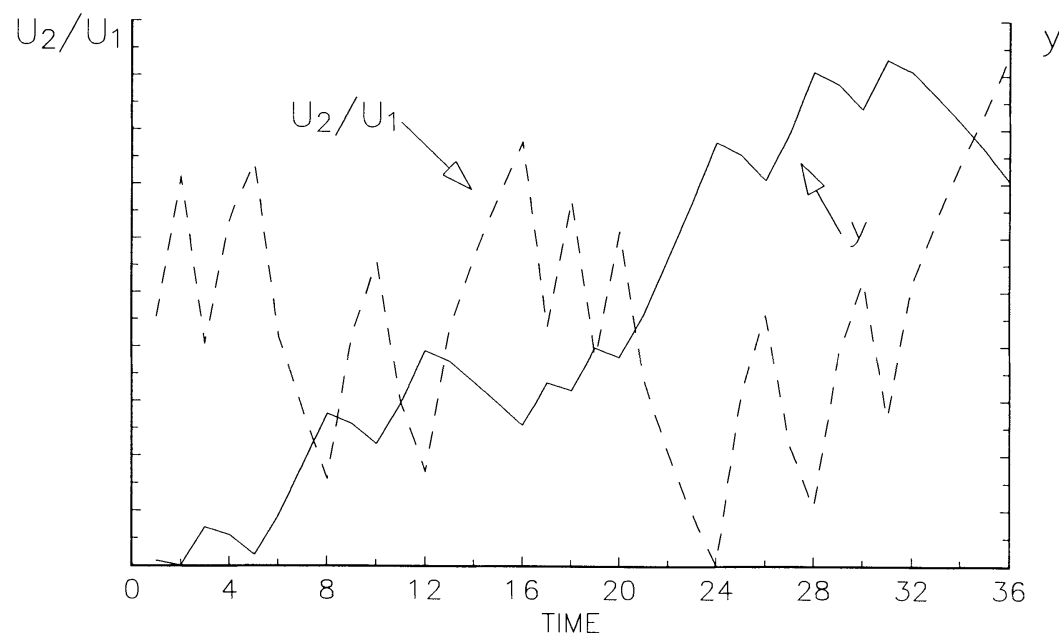

FIG. 3.-Behavior of the price of home goods and output: model 1

2 in table 1 and portrayed in figure $4 .^{13}$ The most striking outcome is that investments now become strongly positively correlated with output. This can be seen in table 1, where the correlations with output for market and household investment are .99 and .96, and in figure 4 , which illustrates the strong positive comovement between the two types of investment.

To interpret this result consider the following expression, which appears in (11), the Euler equation associated with household capital:

$$
H_{1}\left(d^{\prime}, z^{\prime}\left(1-l^{\prime}\right)\right) \frac{U_{2}\left(c^{\prime}, h^{\prime}\right)}{U_{1}\left(c^{\prime}, h^{\prime}\right)}=\omega \frac{d^{\prime \lambda-1}}{\omega d^{\prime \lambda}+(1-\omega) z^{\prime \lambda}\left(1-l^{\prime}\right)^{\lambda}} \frac{1-\theta}{\theta} c^{\prime} .
$$

This term describes the marginal benefit from household investment (measured in terms of market goods). When a technological improvement hits the economy in the current period, $z^{\prime}$ is expected to rise since $z$ follows a random walk. On the one hand, this tends to increase the marginal product of household capital, $H_{1}\left(d^{\prime}, z^{\prime}\left(1-l^{\prime}\right)\right)$. On the other hand, the shadow price of home goods, $U_{2}\left(c^{\prime}, h^{\prime}\right) / U_{1}\left(c^{\prime}, h^{\prime}\right)$, declines because of the induced desire to build up the capital stocks (resulting in a relative scarcity of market goods). Here technological

${ }^{13}$ Note that changing this parameter implies recalculating $\omega$ and $\theta$ using the steadystate equations for model 2. One now obtains $\omega=0.11$ and $\theta=0.26$. For the configuration of parameter values used in model 2 , the marginal welfare cost of capital taxation is 2.6 and that for labor taxation is 0.64 . 


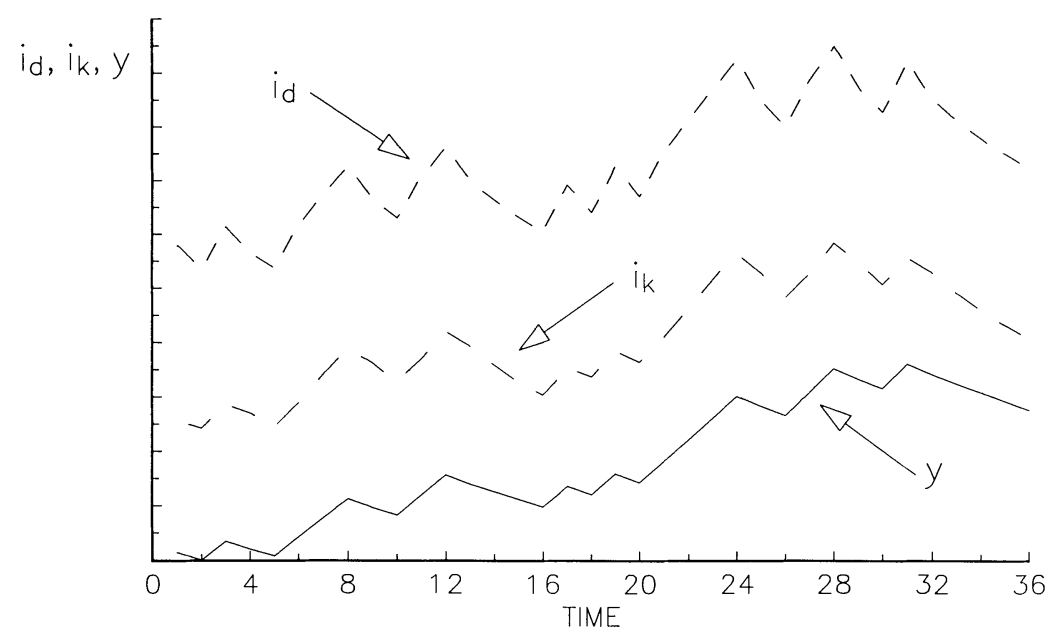

FIG. 4.-Behavior of investment and output: model 2

change has two opposing effects on the marginal benefit of household investment.

In the Cobb-Douglas case, where $\lambda=0$, these two effects cancel each other out, as can be seen in equation (28). It is not surprising then that in model 1 , household investment falls following a positive shock since the latter only improves the marginal benefit of market investment. When $\lambda<0$, the higher complementarity between $d^{\prime}$ and $z^{\prime}\left(1-l^{\prime}\right)$ in next period's household production implies a stronger impact of the shock on the marginal productivity of household capital, $H_{1}\left(d^{\prime}, z^{\prime}\left(1-l^{\prime}\right)\right)$. Observe that (28) is increasing in $z^{\prime}$ when $\lambda<$ 0 . Thus in model 2, the marginal productivity effect becomes more important relative to the relative price effect, and this is the reason behind the more procyclical behavior of household investment.

On the volatility and serial correlation properties of the two investments, model 2 is better able to mimic the data than model 1 . Household investment is now more volatile than business investmentstandard deviations of 4.9 percent and 4.1 percent-and the serial correlation coefficients are larger, with business investment exhibiting stronger serial correlation. Also, the variability of market time is increased from 0.8 percent in model 1 to 1.1 percent, which is, however, still lower than that in the actual data. ${ }^{14}$

${ }^{14}$ Real business cycle models have some difficulty in accounting for the cyclical behavior of factor prices. In the U.S. data, real wages have a standard deviation of 1.1 percent and a correlation with output of .61. The corresponding numbers for the model are 1.1 and .95 . The return on capital has a standard deviation of 6.9 percent 
The intuition behind the increase in the volatility of market time can be obtained by examining the expression shown below representing the marginal value of time at home (cf. eq. [12]):

$$
z H_{2}(d, z(1-l)) \frac{U_{2}(c, h)}{U_{1}(c, h)}=\frac{(1-\omega) z^{\lambda}(1-l)^{\lambda-1}}{\omega d^{\lambda}+(1-\omega) z^{\lambda}(1-l)^{\lambda}} \frac{1-\theta}{\theta} c .
$$

Consider first the case in which the household production technology is Cobb-Douglas $(\lambda=0)$. Here, when a positive technological innovation occurs, the marginal product of household time, $z \mathrm{H}_{2}(d, z(1-$ $l)$ ), increases. This effect, by itself, operates to increase the amount of time spent at home. However, this is not the end of the story, since the relative price of home goods in terms of market goods, $U_{2}(c$, $h) / U_{1}(c, h)$, falls because of the scarcity of market resources-since investment is expanded. This effect works in the direction of increasing market time. In the Cobb-Douglas case, these two forces exactly cancel each other out, and the expression in (29) is independent of $z$. The upshot is that nonmarket time falls following a positive shock since the marginal value of time has increased only in the market sector.

When $\lambda$ is negative, the expression above is decreasing in $z$ so that market time rises, a fortiori, in response to a positive innovation. As the degree of complementarity between time and capital in household production is increased, the effect of technological innovation on the marginal product of nonmarket time is dampened. (In the limiting case in which $\lambda \rightarrow-\infty$, the household production function becomes Leontief and the effect that a positive shock has on nonmarket time's marginal product vanishes.)

The discussion above illustrates the relevance of technological complementarity in household production for the allocation of capital and time across sectors. The analysis suggests that within the CES family of production functions, the degree of substitution between time and capital in household production is less than in the CobbDouglas case, in the sense that this hypothesis allows the model to mimic better the observed pattern of cyclical fluctuations in house-

and a correlation with output of .77 in the data, with the figures for the model being 1.9 percent and .49 . Thus real wages are too procyclical in the model, and the return on capital is not procyclical enough. Benhabib et al. (this issue) address the wage rate observation by allowing the technology shock in the business and household sectors to be different. Ceteris paribus, a positive shock to household technology leads to a rise in the real wage rate but a fall in market output. Consequently, in a model with separate business and household technology shocks, the correlation between the wage rate and output will be reduced. An alternative strategy would be to assume that built into wage payments is an insurance component designed to protect workers against cyclical risk. This would operate to dampen the procyclical movement in wages and make the return on capital move more procyclically. 
hold investment. ${ }^{15}$ Little independent evidence is available to assess the reasonableness of the value chosen for the elasticity of substitution between capital and time in household production. And it would seem difficult on theoretical grounds alone to argue about the appropriate value for this parameter, as indeed it would be for market production parameters too. Clearly, further empirical work is needed to gauge the value of this and other parameters governing household activity.

\section{Concluding Comments}

Two observations about investment in durable consumption goods and housing were stressed in the Introduction: (i) its high level relative to nonresidential business investment and (ii) its procyclical behavior, leading business investment. The aim of this paper was to construct a model that treated the market and nonmarket sectors symmetrically, to see whether it could mimic both these observations, as well as other important features of business fluctuations.

The first observation about the level of home investment (arising from the first moments of the U.S. data) was satisfied by adjusting the parameters of taste and technology. This was part of the calibration procedure followed. It may be noted that in spite of the high level of household capital in the United States, the nonmarket sector is still strongly labor intensive. Capital in the household sector is about 1.1 times higher than in the business sector, but time spent in nonmarket activities is about three times larger than the time spent in market activities. (This is reflected in a higher value for $\alpha$ than for $\omega$.)

In the model, the level of business capital is strongly related to taxation, which applies to business capital income but not to household capital productivity. This tax asymmetry shifts capital toward the nonmarket sector. Given the values of the parameters of the model, found under realistic tax rates, if the taxation of capital is

\footnotetext{
${ }^{15}$ Some limited experimentation with other configurations of parameter values had little success in accounting for the stylized facts on investment. For instance, it may seem reasonable to conjecture that making capital and time more substitutable in market production (when adopting a more general CES form) would have the same effect as making them more complementary in home production. It did not. To get household investment to move more procyclically, the benefit from investing in household capital (the term shown in [28]) must be made to do so too. Experimentation along these lines had little direct influence on this return. In light of this, perhaps making market and home goods more substitutable in consumption could work by dampening the countercyclical movement in the relative price of home goods. (Observe that as $\sigma \rightarrow 1, U_{2} / U_{1} \rightarrow[1-\theta] / \theta$.) This does make household investment move somewhat more procyclically, but at the expense of drastically cutting the volatility of market time and output. Now the return on market time (the term shown on the left-hand side of [29]) becomes less procyclical.
} 
eliminated (being replaced by lump-sum taxation), the ratio of household to business capital along the balanced growth path drops from 1.13 to 0.80 .

The observation about the cyclical behavior of investment was analyzed by simulating the model. Of pivotal importance for the dynamics is the fact that capital goods can be produced only in the market sector. The ramifications of this asymmetry can be illustrated as follows: Suppose that a positive technological innovation hits the economy. In response, the optimal levels of business and household capital increase. Given that capital goods are produced in the business sector only, the induced scarcity of market goods reduces the shadow price of home goods in terms of market goods. A shift of resources to the business sector, in terms of both time and capital, ensues. Hence, this mechanism implies a tendency for business capital to be built first, and only then household capital. This effect operates to produce negative comovement between the two investments, in contrast with the positive covariation observed in the data. The mechanism just described is not a specific feature of this framework. It would be present in any general equilibrium model with household durables. Model 1, which downplays the household production structure, is an example.

In order to overcome the tendency for household investment to move out of phase with business investment, the degree of technical complementarity between time and capital in household production was increased (model 2). This strengthens the positive impact that a technological improvement has on the marginal value of household capital and weakens its effect on the marginal value of household time, thereby promoting an increase in household investment and a reallocation of time toward the market. As a result, household investment moved procyclically and market time became more volatile.

A feature that the present model fails to rationalize is household investment's lead over business investment. Strengthening the effect of shocks on the degree of substitution between labor and capital in home production (i.e., making $\lambda$ more negative) does not affect this timing of events. The introduction of adjustment costs in business capital, which can be thought of as retarding business investment, does not produce the actual type of behavior. Such adjustment costs retard the entire buildup of the two capital stocks, producing only a reduction in general volatility, including that of the two investments.

Given that investment in consumer durables and housing tends to lead other macroeconomic variables over the cycle, household capital plays an interesting macroeconomic role. It seems that a richer model is called for. Production in the business and household sectors may be modeled as requiring the input of services produced in the other sector. For example, households may produce commuting services to 
and from work, which represent an intermediate good in market production. This kind of interaction between the two sectors may be relevant for the cyclical behavior of household investment since it involves an association between business activity and the demand for household capital. Also, it is well known that fluctuations in the amount of time households devote to the market are reflected mainly in the number of jobs rather than in the number of hours worked in existing ones. Hence, reallocation of time from home to market production may require purchases of new cars, homes, appliances, and so forth at early stages of the business cycle. Further investigation of the role of nonmarket activities, especially their implications regarding housing and consumer durable goods, may contribute to the understanding of the origin and propagation of business cycles.

Finally, human capital evolved exogenously in the model. A potential extension would be to endogenize the process governing human capital accumulation (see Ben-Porath 1967). This would permit endogenous growth in the framework. In contrast to physical capital, important components of human capital are produced in the household sector. It is easy to visualize a setting in which human capital production requires the input of goods and services from both the market and nonmarket sectors. Such a framework could be useful for studying the cyclical behavior of investment in human capital and also the role of the household sector in long-run growth.

\section{Appendix}

\section{A. Transformation to a Stationary Representation}

The system of equations (9), (10), (11), and (12)-in conjunction with (3)describes the model's general equilibrium or provides a determination of $c$, $k^{\prime}, d^{\prime}$, and $z l$. Let $c=C(k, d, z ; \boldsymbol{\epsilon}), k^{\prime}=K(k, d, z ; \boldsymbol{\epsilon}), d^{\prime}=D(k, d, z ; \epsilon)$, and $z l$ $=L(k, d, z ; \epsilon)$ represent the solution to (9), (10), (11), and (12), taking account of (3). These allocation rules are homogeneous of degree one in $(k, d, z)$. This is immediate from the system of equations implicitly defining the solution since $U_{1}$ and $U_{2}$ are homogeneous of degree $q-1$, while $F$ and $H$ are homogeneous of degree one and $F_{1}, F_{2}, H_{1}$, and $H_{2}$ are homogeneous of degree zero. Recall from (4) that $z$ is growing across time. The model's variables can be rendered stationary by deflating them by the lagged value of $z$. By defining $x^{*}$ by $x^{*}=x_{t} / z_{t-1}$, for $x=c, k$, and $d$, the decision rules above can be transformed to get $c^{*}=C\left(k^{*}, d^{*}, A \epsilon ; \epsilon\right), k^{* \prime}=K\left(k^{*}, d^{*}, A \epsilon ; \epsilon\right) / A \epsilon$, $d^{* \prime}=D\left(k^{*}, d^{*}, A \epsilon ; \epsilon\right) / A \epsilon$, and $l=L\left(k^{*}, d^{*}, A \epsilon ; \epsilon\right) / A \epsilon$. Now the model's solution is expressed in a stationary form. Observe that these transformed allocation rules will also satisfy (10), (11), and (12)-together with (3)-if $\beta$ and $z$ are changed to $\beta^{*}$ and $z^{*}$, where $\beta^{*} \equiv \beta(A \epsilon)^{q-1}$ and $z^{*} \equiv A \epsilon .{ }^{16}$

${ }^{16}$ For the transformed model, the resource constraint (9) reads

$$
c^{*}+z^{*} k^{*^{\prime}}+z^{*} d^{*^{\prime}}=F\left(k^{*}, z^{*} l\right)+\left(1-\delta_{k}\right) k^{*}+\left(1-\delta_{d}\right) d^{*} \text {. }
$$

This is readily verified by dividing both sides of (9) through by the lagged value of $z$. 


\section{B. Solution Algorithm}

Let the system of equations (10), (11), and (12) defining a stationary solution to the model-once $c^{*}$ and $h^{*}$ have been solved out using (3) and (9) - be more compactly represented by

$$
\Delta\left(k^{*}, d^{*}, k^{* \prime}, d^{* \prime}, l ; \epsilon\right)=\int \Lambda\left(k^{* \prime}, d^{* \prime}, l^{\prime}, k^{* \prime \prime}, d^{* \prime \prime} ; \epsilon, \epsilon^{\prime}\right) d \epsilon^{\prime} .
$$

Here $\Delta: \mathbb{R}_{+}^{6} \rightarrow \mathbb{R}_{+}^{3}$ and $\Lambda: \mathbb{R}_{+}^{6} \rightarrow \mathbb{R}_{+}^{3}$. In order to simulate the model, a set of policy functions of the form $k^{*^{\prime}}=K\left(k^{*}, d^{*} ; \epsilon\right), d^{*^{\prime}}=D\left(k^{*}, d^{*} ; \epsilon\right)$, and $l=$ $L\left(k^{*}, d^{*} ; \epsilon\right)$ must be found that solves this system of integral equations. To do this, an algorithm proposed by Coleman (1988) is employed that approximates the true equilibrium allocation rules over a grid using a multilinear interpolation scheme. ${ }^{17}$

To begin with, assume that the technology shock, $\epsilon$, is an element of the time-invariant set $\mathscr{E}=\left\{\epsilon_{1}, \ldots, \epsilon_{p}\right\}$. Next, restrict the permissible range of values for the stocks of capital and durables to lie in the closed intervals $\left[k_{1}\right.$, $\left.k_{m}\right]$ and $\left[d_{1}, d_{n}\right]$, respectively, and let $\mathscr{K}=\left\{k_{1}, k_{2}, \ldots, k_{m}\right\}$ and $\mathscr{D}=\left\{d_{1}, d_{2}, \ldots\right.$, $\left.d_{n}\right\}$ represent sets of monotonically increasing grid points that span these intervals. Now, make an initial guess for the value of the function $x=X\left(k^{*}\right.$, $\left.d^{*}, \epsilon\right)$, for $x=k^{* \prime}, d^{* \prime}$, and $l$, at each of the $m \times n \times p$ points in the set $\mathscr{K}$ $\times \mathscr{D} \times \mathscr{E}$. Denote the value for the initial guess of the function $X$ at the grid point $\left(k_{h}, d_{i}, e_{j}\right)$ by $X^{0}\left(k_{h}, d_{i}, e_{j}\right)$. A guess for $X$ at other points in its domain $\left[k_{1}, k_{m}\right] \times\left[d_{1}, d_{n}\right] \times \mathscr{E}$ is then constructed through multilinear interpolation (see Press et al. 1986). Specifically, take some point $\left(k^{*}, d^{*}, \epsilon_{j}\right) \in\left[k_{1}, k_{m}\right] \times$ $\left[d_{1}, d_{n}\right] \times \mathscr{E}$. The value of the function $X^{0}$ at the point $\left(k^{*}, d^{*}, \epsilon_{j}\right)$, or $X^{0}\left(k^{*}\right.$, $\left.d^{*}, \epsilon_{j}\right)$, is defined as

$$
\begin{aligned}
X^{0}\left(k^{*}, d^{*}, \boldsymbol{\epsilon}_{j}\right)= & (1-u)(1-v) X^{0}\left(k_{h}, d_{i}, \boldsymbol{\epsilon}_{j}\right)+u(1-v) X^{0}\left(k_{h+1}, d_{i}, \boldsymbol{\epsilon}_{j}\right) \\
& +u v X^{0}\left(k_{h+1}, d_{i+1}, \boldsymbol{\epsilon}_{j}\right)+(1-u) v X^{0}\left(k_{h}, d_{i+1}, \boldsymbol{\epsilon}_{j}\right),
\end{aligned}
$$

where the weights $u$ and $v$ are given by

$$
u=\frac{k^{*}-k_{h}}{k_{h+1}-k_{h}}, \quad v=\frac{d^{*}-d_{i}}{d_{i+1}-d_{i}},
$$

with the grid points $k_{h}, k_{h+1}, d_{i}$, and $d_{i+1}$ being chosen such that $k_{h} \leq k^{*}$ $\leq k_{h+1}$ and $d_{i} \leq d^{*} \leq d_{i+1}$. Thus the interpolated value of $X^{0}$ at $\left(k^{*}, d^{*}, \epsilon_{j}\right)$ is simply taken to be a weighted average of its values at the four nearest grid points. Note that the interpolated function $X^{0}$ is continuous on $\left[k_{1}, k_{m}\right] \times\left[d_{1}\right.$, $\left.d_{n}\right]$.

Given initial guesses for the functions $K, D$, and $L$, denoted by $K^{0}, D^{0}$, and $L^{0}$, respectively, it is straightforward to compute revised guesses $K^{1}, D^{1}$, and $L^{1}$. In particular, for each grid point $\left(k_{h}, d_{i}, \epsilon_{j}\right) \in \mathscr{K} \times \mathscr{D} \times \mathscr{E}$, values for $K^{1}\left(k_{h}, d_{i}, \epsilon_{j}\right), D^{1}\left(k_{h}, d_{i}, \epsilon_{j}\right)$, and $L^{1}\left(k_{h}, d_{i}, \epsilon_{j}\right)$ can be computed by solving the following nonlinear system of equations for $k^{*^{\prime}}, d^{*^{\prime}}$, and $l$ :

$$
\begin{aligned}
\Delta\left(k_{h}, d_{i}, k^{* \prime}, d^{*^{\prime}}, l ; \boldsymbol{\epsilon}_{j}\right)=\sum_{r=1}^{p} \Lambda\left(k^{* \prime}, d^{*^{\prime}}, L^{0}\left(k^{*^{\prime}}, d^{*^{\prime}}, \boldsymbol{\epsilon}_{r}\right),\right. \\
\\
\left.K^{0}\left(k^{*^{\prime}}, d^{*^{\prime}}, \boldsymbol{\epsilon}_{r}\right), D^{0}\left(k^{*^{\prime}}, d^{*^{\prime}}, \boldsymbol{\epsilon}_{r}\right) ; \boldsymbol{\epsilon}_{j}, \boldsymbol{\epsilon}_{r}\right) .
\end{aligned}
$$

${ }^{17}$ Coleman's technique is related to one developed by Baxter (1988) and Danthine and Donaldson (1990). In a nutshell, the principal difference between the method of Baxter and Danthine and Donaldson on the one hand and that of Coleman on the other is that the former restricts the range of the functions describing the laws of motion for the state variables to lie on a grid whereas the latter does not. 
Given values for $k^{* \prime}, d^{* \prime}$, and $l$ at each of the $m \times n \times p$ grid points in $\mathscr{K} \times$ $\mathscr{D} \times \mathscr{E}$, the functions $K^{1}, D^{1}$, and $L^{1}$ can be extended over the entire domain $\left[k_{1}, k_{m}\right] \times\left[d_{1}, d_{n}\right] \times \mathscr{E}$ by interpolation, as was done previously. The functions $K^{1}, D^{1}$, and $L^{1}$ are then used as guesses on the next iteration, with the whole procedure being repeated until the allocation rules have converged.

Once the allocation rules have been obtained, the model can be simulated and various sample statistics for variables of interest computed. Variables need to be converted back to their nonstationary form when the model is simulated. This merely requires multiplying the stationary value of a variable at a point in time by the lagged value of $z$. Thus $x=x_{t}^{*} z_{t-1}$ for $x=c$, $k$, and $d$.

\section{References}

Baxter, Marianne. "Approximating Suboptimal Dynamic Equilibria: An Euler Equation Approach.” Working Paper no. 139. Rochester, N.Y.: Univ. Rochester, Rochester Center Econ. Res., 1988.

Becker, Gary S. "A Theory of the Allocation of Time.” Econ. J. 75 (September 1965): 493-517.

Benhabib, Jess; Rogerson, Richard; and Wright, Randall. "Homework in Macroeconomics: Household Production and Aggregate Fluctuations." J.P.E., this issue.

$\rightarrow$ Ben-Porath, Yoram. "The Production of Human Capital and the Life Cycle of Earnings." J.P.E. 75, no. 4, pt. 1 (August 1967): 352-65.

Christiano, Lawrence J. "Why Does Inventory Investment Fluctuate So Much?” J. Monetary Econ. 21 (March/May 1988): 247-80.

Coleman, Wilbur John. "Money, Interest, and Capital in a Cash-in-Advance Economy." International Finance Discussion Paper no. 323. Washington: Board Governors, Fed. Reserve System, 1988.

Danthine, Jean-Pierre, and Donaldson, John B. "Efficiency Wages and the Business Cycle Puzzle." European Econ. Rev. 34 (November 1990): 1275-1301.

_. "Methodological and Empirical Issues in Real Business Cycle Theory." Manuscript. New York: Columbia Univ., 1991.

Ghez, Gilbert R., and Becker, Gary S. The Allocation of Time and Goods over the Life Cycle. New York: Columbia Univ. Press (for NBER), 1975.

Gronau, Reuben. "Home Production-a Survey." In Handbook of Labor Economics, vol. 1, edited by Orley C. Ashenfelter and Richard Layard. Amsterdam: Elsevier, 1986.

$\rightarrow$ Hansen, Gary D. "Indivisible Labor and the Business Cycle." J. Monetary Econ. 16 (November 1985): 309-27.

$\rightarrow$ Hausman, Jerry A., and Poterba, James M. "Household Behavior and the Tax Reform Act of 1986."J. Econ. Perspectives 1 (Summer 1987): 101-19.

$\rightarrow$ Jorgenson, Dale W., and Yun, Kun-Young. "Tax Policy and Capital Allocation." Scandinavian J. Econ. 88, no. 2 (1986): 355-77.

King, Robert G.; Plosser, Charles I.; and Rebelo, Sergio T. "Production, Growth and Business Cycles: I. The Basic Neoclassical Model." J. Monetary Econ. 21 (March/May 1988): 195-232. (a)

- "Production, Growth and Business Cycles: II. New Directions." J. Monetary Econ. 21 (March/May 1988): 309-41. (b)

Kydland, Finn E. "Labor-Force Heterogeneity and the Business Cycle." Carnegie-Rochester Conf. Ser. Public Policy 21 (Autumn 1984): 173-208. 
$\rightarrow$ Kydland, Finn E., and Prescott, Edward C. "Time to Build and Aggregate Fluctuations." Econometrica 50 (November 1982): 1345-70.

$\rightarrow$ Long, John B., Jr., and Plosser, Charles I. "Real Business Cycles." J.P.E. 91 (February 1983): 39-69.

Macklem, Tiff. "Durable and Non-durable Consumption Goods, and Asset Returns in an Artificial Economy." Manuscript. Ottawa: Bank of Canada, 1989.

Prescott, Edward C. "Theory Ahead of Business Cycle Measurement." Fed. Reserve Bank Minneapolis Q. Rev. 10 (Fall 1986): 9-22.

Press, William H.; Flannery, Brian P.; Teukolsky, Saul A.; and Vetterling, William T. Numerical Recipes: The Art of Scientific Computing. Cambridge: Cambridge Univ. Press, 1986.

$\rightarrow$ Rogerson, Richard. "Indivisible Labor, Lotteries and Equilibrium." J. Monetary Econ. 21 ( January 1988): 3-16.

Sargent, Thomas J. "Tobin's $q$ and the Rate of Investment in General Equilibrium.” Carnegie-Rochester Conf. Ser. Public Policy 12 (Spring 1980): 107-54. 